BMJ Paediatrics Open

\section{Developing a competence framework for psychological interventions in a multidisciplinary paediatric context}

To cite: Roth AD, Donnan J. Developing a competence framework for psychological interventions in a multidisciplinary paediatric context. BMJ Paediatrics Open 2019;3:e000447. doi:10.1136/ bmjpo-2019-000447

Received 24 January 2019 Revised 21 May 2019 Accepted 28 May 2019
Check for updates

\section{(c) Author(s) (or their} employer(s)) 2019. Re-use permitted under CC BY-NC. No commercial re-use. See rights and permissions. Published by BMJ.

${ }^{1}$ Research Department of Clinical, Educational and Health Psychology, University College London, London, UK ${ }^{2}$ NHS Education for Scotland, Edinburgh, UK

Correspondence to Anthony David Roth, Research Department of Clinical, Educational and Health Psychology, University College London, London WC1E 6BT, UK; a.roth@ucl.ac.uk

\section{ABSTRACT}

This paper describes the development and content of a competence framework for psychological interventions, intended to apply to healthcare workers of all disciplines working in a paediatric context. To achieve this, a review of the literature was used to indicate where current interventions had evidence for efficacy; this scoping exercise was complemented by an expert reference group (ERG) whose role was to offer professional advice on areas where the evidence base is not strong but where the field commonly employs interventions. Iterative peer review of the emerging framework was undertaken both by the ERG and external peer reviewers selected for their expertise in the field. The characteristics of the completed framework are presented, along a discussion of the uses to which it can be put. The framework is best seen as a practitioner support tool, providing a basis for training and practice in paediatric contexts.

\section{INTRODUCTION}

The context for the development of the paediatric competence framework

Children and young people with health conditions (and their families) experience four times more psychological distress than their healthy peers. ${ }^{1}$ The process of adjusting to and coping with a medical condition is a challenge. $^{2}$

There is a growing evidence base for the effectiveness of psychological interventions in paediatric populations. ${ }^{3}$ This indicates that responding both to psychological and physical needs can not only improve outcomes for children and their families but also reduce overall costs ${ }^{45}$ All healthcare staff have a role in delivering psychosocial and psychologically informed care, in line with the boundaries of their own existing role and as part of routine care. However, there has been limited guidance on how this can be achieved across professions: most competence frameworks developed hitherto set out criteria for specific clinical training programmes, and as a consequence are profession specific (eg, see Rodolfa $\left.e t a l^{6}\right)$.

The framework described in this paper identifies psychological knowledge and skills applicable to all workers in a paediatric context, as well as the competences required to apply more specialist psychological interventions. Importantly, it assumes that the ability of a worker to undertake an intervention is determined by their training rather than by their job title.

\section{DEVELOPING THE FRAMEWORK \\ Patient involvement}

Patients were not involved in the design or development of the framework.

\section{Principles used to develop the framework}

The methodology used to develop the competence frameworks conforms to a number of key principles ${ }^{7}$ :

- As far as possible, the framework is evidence based, such that there is reason to believe that the competences it sets out are likely to make a difference, for example, because they have been included in the manual of a successful clinical trial. Of course, there are limits to this aspiration, partly because there is only limited research that speaks to the efficacy of specific competences as applied to specific aspects of paediatric practice. Thus, while evidence for efficacy is strong in some areas (eg, the promotion of concordance with treatment regimens or the management of procedural distress) ${ }^{8}$ in other areas, efficacy can only be inferred on the basis of the application of techniques in other clinical contexts. Here, the role of expert professional opinion is critical in winnowing the evidence and supplementing it where required (a process that mirrors models of evidence-based practice) ${ }^{9}$

- The framework is intended to be indicative rather than prescriptive, retaining the role of clinical judgement. It is a clinical support tool that identifies best practice but also allows for informed application 
as to when, whether and how competences are put into action.

- Frameworks are subject to oversight from an expert reference group (ERG) (membership of the ERG comprised Sally Benson, Emma Blake, Zoe Cameron, Gillian Colville, Rachel Cooke, Nicola Doherty, Janie Donnan, Nicola Herberholz, Isobel Heyman, Hilary Maddox, Irene O'Donnell, Stephen Pilling, Anthony Roth, Penny Titman and Ingram Wright) composed of experts in the field, usually researchers, trainers, expert practitioners and experts by experience, ensuring that the shape of the product is proactively guided by expert opinion. Although the ERG has a role in peer-reviewing emerging content, it has a broader focus, considering as it does the structure and therefore the areas embraced by the framework.

- The content of the framework is subjected to review both by members of the ERG and by 'external' peer reviewers with recognised authority in the field. The role of all reviewers is to identify areas where the draft framework is unclear, in error or contains significant gaps, but the additional benefit of external reviewers is that it ensures that the practice described in the framework reflects a consensus among researchers and clinicians (and does not contain approaches that could be seen as idiosyncratic).

- The framework is set at a single level, describing what would be expected of a competent clinician. This is in contrast to frameworks that identify a tier of skill levels, for example, from novice through to expert. Although there can be merit in a tiered approach, such distinctions can be arbitrary and misleading, in that to be effective, interventions require the deployment of a coherent hierarchy of skills; deciding which of these are expected only of more experienced professionals presents a significant challenge.

- Organising competences: a major challenge is to present competences in a way that makes them accessible to their intended audience. Perhaps the least helpful approach is simply to list competences, which requires readers to work out some sort of organisational structure, something that they may find particularly challenging if they are not already familiar with the area. For this reason, our competence frameworks are set out as a 'map' that identifies all the areas of knowledge and skill, organises them into a series of domains and helps to identify the ways in which the sets of competences inter-relate: figure 1 shows the basic outline structure. The initial domains identify underpinning competences that permeate all that follows - the basic areas of knowledge that are required, along with the basic professional competences that govern practice. These areas are followed by a description of the generic clinical skills required to assess, to formulate and, on this basis, to identify plans for interventions, and the interventions themselves. The final domain comprises 'metacompetences' - the procedural rules that a practitioner uses to identify whether, how and in what way competences are executed. Metacompetences invariably involve judgement, and their presence explicitly signals that clinical work is more than a matter of simple adherence to protocols.

The map is intended to be holistic, clustering areas of competence together and illustrating the way in which sets of competences need to be entrained in order to deliver an intervention. One risk is that it could be read as progressing from an initial set of 'simple'

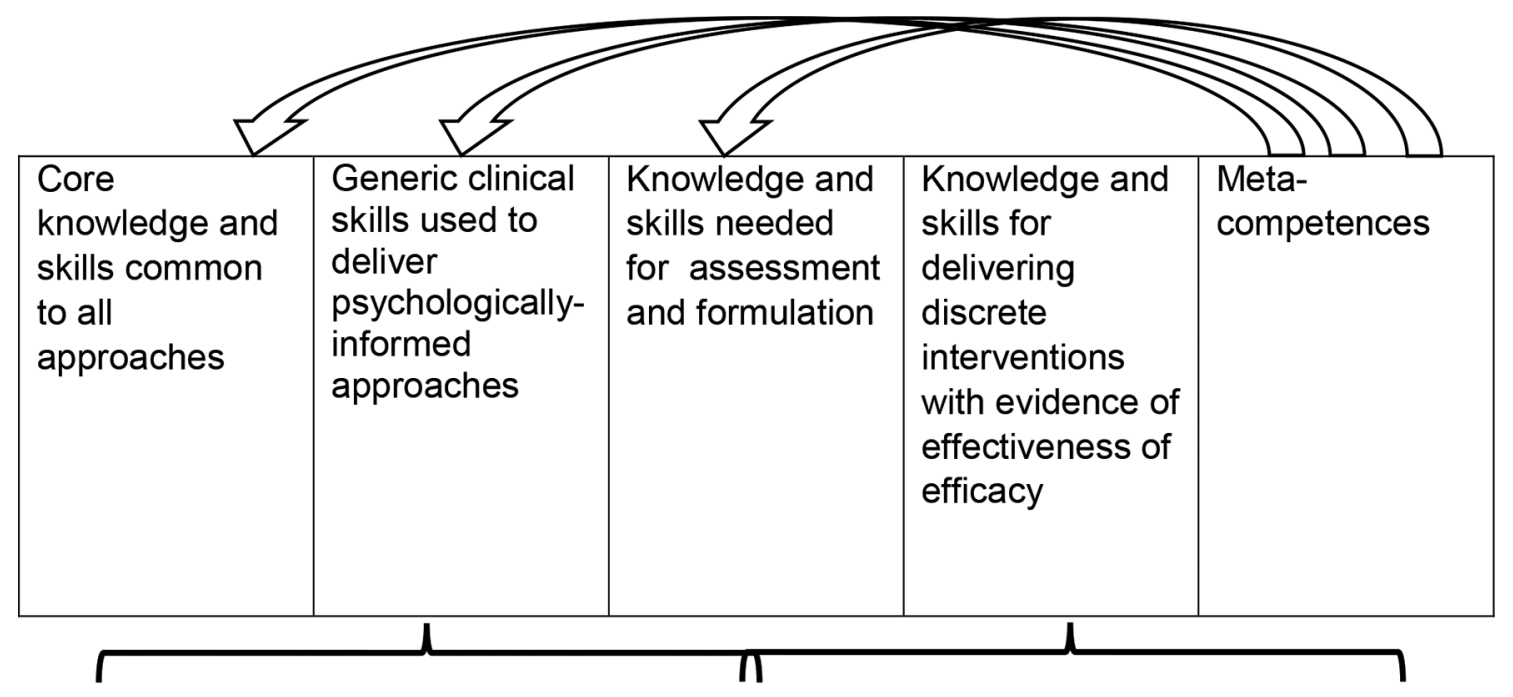

$$
\begin{aligned}
& \text { Generic underpinning skills } \\
& \text { applicable to all practitioners }
\end{aligned}
$$

More specific/ specialist skills

Figure 1 Outline structure of competence maps. 
competences, building to more sophisticated areas of application. This would be unhelpful because any approach or intervention is dependent on successful execution of underpinning skills, many of which are difficult to acquire and maintain; equally, metacompetences apply across the framework and permeate all areas of activity.

- 'Extracting' competence statements: competence statements are derived from a number of sources, giving primacy to manuals from clinical trials that indicate evidence of efficacy, but where these are not available or do not cover relevant areas of competence, then other sources are used, for example, training materials and textbooks. There are challenges to the extraction process. Source materials come in a range of formats, with marked variation in terms of length, intent and structure. Sometimes, these are protocols, indicating in great detail what should be happening in each session. Often, however, source material is set out at a much more conceptual level, drawing attention to the elements of an intervention and to the management of common clinical issues and impasses, but clearly assuming that the reader has prior clinical experience (and so not providing details of specific skills). This means that extracting competences requires the application of clinical knowledge, followed by peer review in order to ensure that practice is being described accurately and clearly, and at the right level of detail. In addition, extraction involves identifying the principles that lie behind high-level statements about clinical strategies, ensuring that descriptions of any skill convey a sense of why something is done, rather than listing behaviours without giving an overview of the rationale for an action. This is an important part of the extraction and development process, hopefully creating a framework that supports intelligent application of competences, rather than rote adherence.

- Setting the level of competence statements: a key aim is to write the competence statements at a level that enables users to understand what it is they need to know and do in order to carry out an activity. As such, they are concise, explain technical references as they arise (so that users do not have to cross-refer to other sources in order to understand what is required of them) and give sufficient detail to identify what a practitioner actually needs to do.

- Peer review of competence statements: as is usual when developing clinical guidelines, peer review of an emerging product is critical. Some of this comes from the ERG, but in addition, national and international experts are invited to comment on the work. The intent is to arrive at an expert consensus regarding the accuracy and scope of the framework, as well as its sensitivity to the needs of the people who will be the recipients of any clinical service.
THE PAEDIATRIC FRAMEWORK FOR PSYCHOLOGICAL

\section{INTERVENTIONS IN A MULTIDISCIPLINARY CONTEXT}

The framework (and so the specific competences) should be viewed online (at www.ucl.ac.uk/core/competence-frameworks/); what follows is a synoptic guide to its content.

Figure 2 shows the map of competences for working in a paediatric context. It is organised into a series of domains, each containing a set of 'boxes' that identify each area of competence with a 'headline' that indicates its content. Users access the detailed competence lists associated with each 'box' by following the hyperlinks embedded in the map.

Taken together, the skills in the initial two domains are relevant to all paediatric workers who are delivering psychologically informed care; their description as 'underpinning' skills draws attention to the fact that they secure the integrity of all subsequent assessments and interventions.

The first domain identifies 'core competences for work with children and young people', and includes the underpinning knowledge and skills needed to

- Orient them to the styles of work that characterise contacts with children, young people and their families.

- Liaise with colleagues and other agencies.

- Apply the professional and legal frameworks that exercise governance over procedures with children and young people.

The second domain identifies 'core knowledge and competences for working with children and young people with physical health problems', including

- Knowledge of presenting conditions and the impact of physical conditions at different developmental stages.

- Knowledge of models of 'medically unexplained' symptoms, adjustment and behaviour change.

- Knowledge of the ways in which self-management materials can be developed and employed.

The third domain ('generic therapeutic competences') identifies the competences required to manage clinical sessions and any form of psychological intervention, and outlines the repertoire of engagement and communication skills that underpin effective working across all interventions and therapy modalities.

The fourth domain relates to assessment, formulation, engagement and planning. It identifies the 'assessment, formulation, engagement and planning' skills expected of all caseholders who are delivering psychological therapies. Some of these competences are also relevant to all paediatric healthcare workers because they will aid psychological understanding of the problems presented by children and families in a paediatric context. A subsection of this domain focuses on skills needed to coordinate care within and across teams.

The fifth domain identifies a set of 'specialist assessments' conducted by staff with relevant roles and prior 


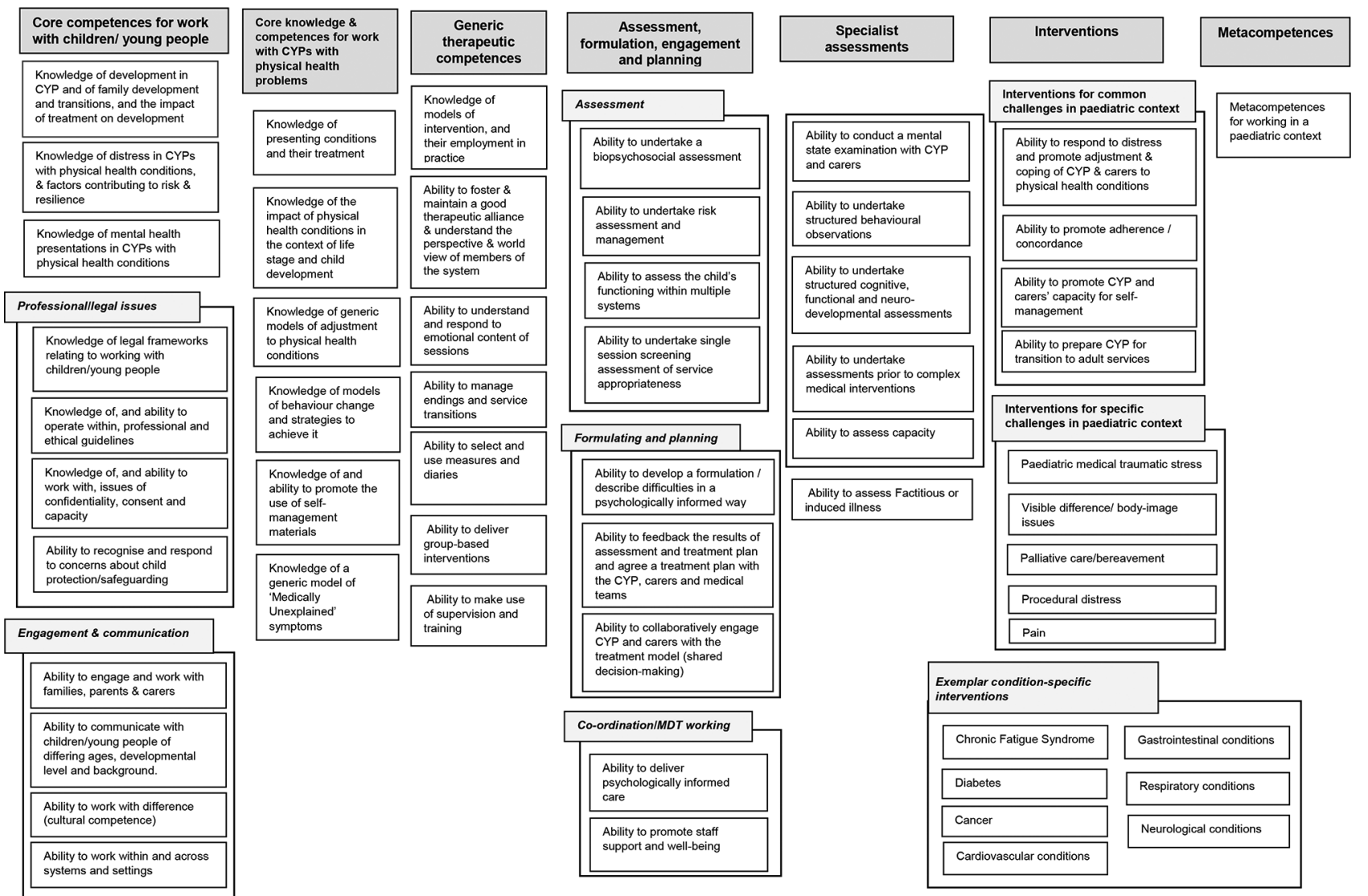

Figure 2 Map of competences for psychological interventions in a multidisciplinary paediatric context. CYP, children/young people; MDT, multi disciplinary team.

training; as such, there is no expectation that all members of a team will be able to carry them out.

The next domain details psychologically informed interventions and contains three subsections, all of which have relevance across multidisciplinary healthcare staff, but in differing degrees (dependent on their role). While the knowledge and assessment sections of these subdomains will be applicable to most healthcare staff, the more specific intervention skills will only be applicable to those trained to deliver the psychological therapy that the competency describes. This section identifies generic interventions for challenges that commonly arise in paediatric healthcare but also identifies potential differences in the psychological support requirements of children with different types of health problems, since these will bring with them specific psychological issues that paediatric healthcare staff should be aware of. As such, it is subdivided to cover

- Interventions for challenges that commonly arise in a paediatric context and that are relevant across almost all physical health conditions (such as promoting self-management skills or responding to distress).

- Specific challenges that arise in some, but not all, conditions (such as paediatric medical trauma, coping with visible difference or addressing procedural distress).

- 'Exemplar condition-specific interventions' for which there is research evidence of efficacy that points to the benefit of the 'package' of skills being described. These are 'exemplars' in the sense that they illustrate the ways in which care is tailored to a number of specific conditions, rather than being an exhaustive list of all possible condition-specific interventions.

The final domain of the framework focuses on metacompetences, so-called because they permeate all areas of practice, from underpinning skills through to specific interventions. They involve making procedural judgements and are important because effective implementation requires more than the rote application of a simple set of 'rules': metacompetences attempt to spell out some of the more important areas of judgement being made.

Also published on the website is a background document that details the methodology used to develop the framework and includes a synopsis of the competences included within it.

\section{Applying the competence framework Training}

Training and supervision is a vital component in the effective delivery of psychologically informed approaches and psychological therapies. Practitioners need an appropriate orientation and attitude towards the work, as well as knowledge about a particular area of intervention and the repertoire of skills needed to execute it-in a sense, the capacity to do the right thing, in the right way. The framework can support this because it is relatively easy 
to translate into a curriculum-each area of competence is structured into a logical order that moves from basic areas of knowledge through to the specifics of application.

\section{Supervision}

Used in conjunction with the competence framework for supervision (accessed at www.ucl.ac.uk/clinicalpsychology/CORE/supervision_framework.htm), the paediatric framework provides a useful tool to improve the quality of supervision by focusing it on a set of competences that are known to be associated with the delivery of effective treatments.

\section{Commissioning}

The framework can contribute to the effective use of healthcare resources by enabling commissioners to specify both the appropriate levels and the range of competences that need to be demonstrated by a particular paediatric service, as well as the appropriate skill mix of staff needed to be employed within it, in order to meet identified local needs.

\section{Service organisation: the management and delivery of services}

The framework identifies competences that (wherever possible) are evidence based, and describe best practicethe activities that individuals and teams should follow to deliver psychologically informed care and psychological interventions, and enables the identification of

- Key competences required by a practitioner to deliver psychologically informed approaches and interventions across paediatric contexts.

- The competences that a team would need to meet the scope of the service they aim to deliver and the needs of the populations with whom they work.

- The likely training and supervision competences required by those delivering and the service.

\section{Linking to clinical guidelines}

Because the framework converts general descriptions of clinical practice into a set of concrete specifications, it can link the advice set out in clinical guidelines and national and local policy documents with the interventions actually delivered. Furthermore, this level of specification carries the promise that the interventions delivered will be closer in form and content to those of research trials on which claims for the efficacy of specific interventions rest. In this way, it could help to ensure that interventions are provided in a competent and effective manner.

\section{DISCUSSION}

A key strength of the framework is that it is led by the evidence base, and where this falters is supplemented by multidisciplinary expert clinical opinion. It clearly details the 'why', 'what' and the 'how' of any intervention, and is designed to be accessible across professions, acting as a clinical support tool that supports the effective delivery of psychologically informed practice. This is something that many staff are already doing: for example, the psychological and emotional support that is delivered every day by ward nurses to children, young people and families experiencing high levels of distress and anxiety. However, this care is often delivered without formal training, reliant on intuition and experience. The framework sets out to describe the relevant knowledge and skills in an accessible format for all staff, irrespective of experience, providing guidance for training and skills development.

Reflecting its focus on promoting psychological wellbeing and adjustment, the framework does not include interventions for specific mental health difficulties. However, it is important to hold in mind that children with physical health problems have elevated rates of common mental health problems, and there is good reason to assume that they would respond to the same psychological interventions for mental health difficulties as those without physical health difficulties. The framework recognises this by cross-referring to a parallel framework for working with children in mental health services (https://www.ucl.ac.uk/pals/research/clinical-educational-and-health-psychology/research-groups/core/ competence-frameworks-11).

One limitation of the framework is that service users (in this case, children and their carers) were not involved in its development. There are major benefits to service user involvement, not least a sensitivity to the 'stance' being taken in relation to users, the inclusion of areas seen as salient by service users but potentially overlooked by professionals, an emphasis on the adaptation of technique to match the needs of individuals and 'editorial' scrutiny to assure that the language being used is accessible. The framework for work with children in mental health services did involve service users who were sensitised to these various issues, but there is still the risk that some sections could inadvertently fail to address these (and other) areas of concern.

Some may have concerns that listing competences for working within paediatric healthcare risks turning psychological and emotional care into a set of tasks, detracting from the compassion staff need to experience and demonstrate to support children and families through what can be highly distressing and emotive situations. In fact, we hope the framework does the opposite, helping staff develop a clearer understanding of how best to help children, young people and their families navigate challenges, tailoring their approach to best meet the needs of individual families, and so supporting the paediatric workforce to recognise and respond to the psychological needs of those for whom we care.

Funding The authors have not declared a specific grant for this research from any funding agency in the public, commercial or not-for-profit sectors.

Competing interests None declared.

Patient consent for publication Not required.

Provenance and peer review Not commissioned; externally peer reviewed.

Data sharing statement There are no data in this work. 
Open access This is an open access article distributed in accordance with the Creative Commons Attribution Non Commercial (CC BY-NC 4.0) license, which permits others to distribute, remix, adapt, build upon this work non-commercially, and license their derivative works on different terms, provided the original work is properly cited, appropriate credit is given, any changes made indicated, and the use is non-commercial. See: http://creativecommons.org/licenses/by-nc/4.0/.

\section{REFERENCES}

1. Hysing M, Elgen I, Gillberg C, et al. Chronic physical illness and mental health in children. Results from a large-scale population study. $J$ Child Psychol Psychiatry 2007;48:785-92.

2. Mercer A, O'Curry S, Donnan J, et al. Delivering psychological services for children and young people with physical health needs and their families. The Child and Family Clinical Psychology Review 2015;3:71-81.

3. Fonagy PT, Cottrell, D M, et al. What works for whom: A critical review of treatments for children and adolescents. 2nd edition. New York: Guilford Press, 2015
4. McGrady ME, Ryan JL, Gutiérrez-Colina AM, et al. The impact of effective paediatric adherence promotion interventions: systematic review and meta-analysis. Child Care Health Dev 2015;41:789-802.

5. Evans JR, Benore E, Banez GA. The Cost-Effectiveness of Intensive Interdisciplinary Pediatric Chronic Pain Rehabilitation. J Pediatr Psychol 2016;41:849-56.

6. Rodolfa E, Bent R, Eisman E, et al. A cube model for competency development: Implications for psychology educators and regulators. Prof Psychol-Res PR 2005;36:347-54.

7. Roth $A D$, Pilling S. Using an evidence-based methodology to identify the competences required to deliver effective cognitive and behavioural therapy for depression and anxiety disorders. Behav Cogn Psychother 2008;36:129-47.

8. NHS Education Scotland. The Matrix - A Guide to Delivering Evidence-Based Psychological Therapies in Scotland, 2015. Available: www.nes.scot.nhs.uk/media/606133/thematrix-final.pdf

9. Roth $A D$, Parry G, Fonagy P. Psychotherapy research, health policy and service provision. In: Roth AD, Fonagy P, eds. What works for whom? A critical review of psychotherapy research. 2nd edition. New York: Guilford Press, 2005: pp 43-65. 